\title{
Small Clusters of Electrically Coupled Neurons Generate Synchronous Rhythms in the Thalamic Reticular Nucleus
}

\author{
Michael A. Long, Carole E. Landisman, and Barry W. Connors \\ Department of Neuroscience, Division of Biology and Medicine, Brown University, Providence, Rhode Island 02912
}

\begin{abstract}
The inhibitory neurons of the thalamic reticular nucleus (TRN) contribute to the generation of widespread oscillations in the thalamocortical system. Some TRN neurons are interconnected by electrical synapses, and here we tested the possibility that electrical synapses mediate rhythmic synchrony in juvenile rats. Both the incidence and strength of electrical coupling between pairs of TRN neurons were a steep function of intersomatic distance, and coupling was absent at distances $>40 \mu \mathrm{m}$. Presynaptic spike bursts evoked much larger electrical postsynaptic potentials than did single presynaptic spikes. Activation of metabotropic glutamate receptors (mGluRs) with a bath-applied agonist or an endogenous ligand released during tetanic stimulation induced robust rhythms of the subthreshold membrane potential, with a mean frequency of $\sim 10 \mathrm{~Hz}$. In the absence of fast chemical synaptic transmission, subthreshold rhythms and the action potentials that they evoked were well synchronized between closely spaced, electrically coupled pairs; rhythms in noncoupled cells were not synchronized. The results suggest that electrical synapses can coordinate spindle-frequency rhythms among small clusters of mGluR-activated TRN cells.
\end{abstract}

Key words: nucleus reticularis thalami; thalamus; gap junction; electrical synapse; synchrony; rhythms; metabotropic glutamate receptor

\section{Introduction}

The GABAergic neurons that comprise the thalamic reticular nucleus (TRN) surround and inhibit the neurons in the thalamic relay nuclei (Steriade et al., 1997; Crabtree, 1999). TRN neurons often participate in widespread rhythmic, synchronized activity that encompasses other thalamic nuclei and the neocortex (Steriade et al., 1987; von Krosigk et al., 1993). The prevalence and frequency of TRN rhythms depend on various factors, including behavioral state (Steriade et al., 1993). Under certain circumstances the TRN may also generate pathological rhythms, such as those associated with spike-wave forms of seizures (Williams, 1953; Avanzini et al., 2000; McCormick and Contreras, 2001; Slaght et al., 2002).

The mechanisms of rhythm generation and synchronization within the TRN are not fully understood. It is possible that the TRN itself is intrinsically rhythmogenic (Steriade et al., 1987); however, when isolated in vitro, the TRN has not been observed to oscillate spontaneously (von Krosigk et al., 1993; Jacobsen et al., 2001). Axons originating outside the TRN, such as glutamatergic afferents from the neocortex and thalamic relay nuclei, may help to synchronize the firing of TRN cells (Destexhe et al., 1998; Bal et al., 2000; Blumenfeld and McCormick, 2000). Synaptic connectivity within the TRN is also likely to play an important

Received July 16, 2003; revised Nov. 15, 2003; accepted Nov. 15, 2003.

This research was supported by the National Institutes of Health (NS25983, DA12500, NS40528). We thank Saundy Patrick for outstanding technical help and Michael Beierlein for helpful comments on this manuscript.

Correspondence should be addressed to Barry W. Connors, Department of Neuroscience, Box 1953, Brown University, Providence, RI 02912. E-mail: bwc@brown.edu.

M. A. Long's present address: Department of Brain and Cognitive Sciences, E19-528, Massachusetts Institute of Technology, 77 Massachusetts Avenue, Cambridge, MA 02139-4307.

DOI:10.1523/JNEUROSCI.3358-03.2004

Copyright $\odot 2004$ Society for Neuroscience $\quad$ 0270-6474/04/240341-09\$15.00/0 role. Anatomical (Deschenes et al., 1985; Yen et al., 1985; De Biasi et al., 1988; Liu and Jones, 1999) and physiological (Ulrich and Huguenard, 1996; Sanchez-Vives et al., 1997; Shu and McCormick, 2002) evidence suggest that TRN neurons form mutually inhibitory GABAergic synapses. Although the structure, function, and extent of inhibitory synapses within the TRN remain somewhat controversial (Wang and Rinzel, 1993; Pinault et al., 1995; Huntsman et al., 1999; Landisman et al., 2002; Shu and McCormick, 2002), it is widely accepted that these synapses affect the coordination of spiking among TRN neurons.

We discovered recently that many neurons of the TRN are interconnected by electrical synapses (Landisman et al., 2002). The biophysical properties of electrical coupling between pairs of TRN neurons are very similar to those of electrical coupling between pairs of inhibitory interneurons in neocortex (Galarreta and Hestrin, 1999; Gibson et al., 1999). Coupling among both TRN neurons (Landisman et al., 2002) and neocortical interneurons (Deans et al., 2001) is dependent almost entirely on expression of the gap junction protein connexin36 (Cx36). Fast presynaptic signals, notably action potentials, evoke small electrical postsynaptic potentials that can mediate synchronized spiking between pairs of TRN neurons. Slower signals, such as the depolarizing-hyperpolarizing envelope of an intrinsic burst, are transmitted particularly well by electrical synapses (Landisman et al., 2002). These properties suggest that electrical synapses may be a significant feature of TRN circuitry and thalamocortical processing.

The work that we describe here helps to clarify the importance of TRN electrical coupling in two ways. First, we studied the spatial organization of coupling and found that it was very strongly dependent on intersomatic distance; electrically coupled clusters of TRN neurons are quite small compared with those in 
the neocortex. Second, we induced rhythmic activity in a subpopulation of TRN neurons by activating metabotropic glutamate receptors. The synchronization of induced rhythms was very localized and depended on electrical coupling. We propose that electrical synapses coordinate the rhythmic activity of small clusters of neurons within the TRN.

\section{Materials and Methods}

Thalamocortical slices (Agmon and Connors, 1991), 350-400 $\mu \mathrm{m}$ thick, were prepared from Sprague Dawley rats aged postnatal days 12-15. Slices were visualized using either a Zeiss Axioskop (Oberkochen, Germany) or an Olympus Optical BX50WI (Tokyo, Japan) with a Hamamatsu (Hamamatsu City, Japan) CCD camera using infrareddifferential interference contrast (IR-DIC) in a submerged recording chamber at $32-33^{\circ} \mathrm{C}$. The bathing solution contained (in $\mathrm{mm}$ ): $126 \mathrm{NaCl}$, $3 \mathrm{KCl}, 1.25 \mathrm{NaH}_{2} \mathrm{PO}_{4}, 2 \mathrm{MgSO}_{4}-7 \mathrm{H}_{2} \mathrm{O}, 26 \mathrm{NaHCO}_{3}, 10$ dextrose, and 2 $\mathrm{CaCl}_{2}$. Micropipettes were filled with (in $\mathrm{mM}$ ): $130 \mathrm{~K}$-gluconate, 0.2 EGTA, $4 \mathrm{KCl}, 2 \mathrm{NaCl}, 10$ HEPES, 0-10 sucrose, 4 ATP-Mg, 0.3 GTP-Tris, and 14 phosphocreatine-Tris. Recordings were performed in current clamp using Axoprobe amplifiers (Axon Instruments, Foster City, CA). Extracellular stimulation was delivered through a small bipolar extracellular electrode placed on the internal capsule. Each shock was $200 \mu \mathrm{sec}$ long, and a 20-30 shock train was delivered at $100 \mathrm{~Hz}$.

The following drugs were used in this study: the NMDA receptor antagonist D,L-2-amino-5-phosphopentanoic acid (AP5; Sigma, St. Louis, $\mathrm{MO}$ ), the AMPA/kainite receptor antagonist 6,7-dinitroquinoxaline-2,3dione (DNQX; Sigma), the $\mathrm{GABA}_{\mathrm{A}}$ antagonist picrotoxin (Sigma), the metabotropic glutamate receptor (mGluR) agonist (groups I and II) (1S,3R)-1-aminocyclopentane-1,3-dicarboxylic acid (ACPD; Tocris, Bristol, UK), and the mGluR antagonist (groups I and II) (S)- $\alpha$-methyl-4carboxyphenylglycine [ $(S)$-MCGP; Tocris]. All experiments were performed with AP5 $(50 \mu \mathrm{M})$, DNQX $(20 \mu \mathrm{M})$, and picrotoxin $(20 \mu \mathrm{M})$ to eliminate fast synaptic transmission. To induce rhythmic activity, the mGluR (groups I and II) agonist ACPD (Tocris) $(50 \mu \mathrm{m})$ was applied for 1-3 min; 1 mM MCPG was used to block rhythmic activity.

Several aspects of the analysis, including the algorithms used to calculate auto- and cross-correlation values for subthreshold behavior, have been reported previously (Gibson et al., 1999; Beierlein et al., 2000; Long et al., 2002). Acquisition and analysis software was programmed by Jay R. Gibson (University of Texas, Southwestern Medical Center). To estimate the strength of coupling, 10-20 hyperpolarizing pulses ( $600 \mathrm{msec},-200$ pA) were applied sequentially to each cell. The deflection in the stimulated cell $\left(\Delta V_{1}\right)$ and in its coupled neighbor $\left(\Delta V_{2}\right)$ were averaged, and a coupling coefficient was estimated $\left(\Delta V_{2} / \Delta V_{1}\right)$. Pairs with coupling coefficients $>0.008$ were considered to be electrically coupled. Before correlation and power spectrum calculations, all data were bandpass filtered from 1.5 to $70 \mathrm{~Hz}$ using a finite impulse response filter. To estimate the degree of correlation between the subthreshold activity of a pair of cells, five $2 \mathrm{sec}$ epochs of ACPD-induced rhythmicity were tested, and the cross-correlation values at time 0 were averaged (bin size $=2 \mathrm{msec}$ ). The rhythmicity index, used to assess rhythm strength, was estimated by quantifying the amplitude of the autocorrelogram side peak for a $5 \mathrm{sec}$ epoch during ACPD-induced rhythmicity (see Fig. 3). Power spectra were also constructed for these epochs, and the peak value was defined as the dominant frequency of the recorded cell. We used spike crosscorrelations (bin width $=5 \mathrm{msec}$ ) to display the degree of synchrony between ACPD-induced action potentials. Correlated spiking was quantified by normalizing the central bin to the mean number of spikes per bin for the entire sample (see Fig. $6 B$ ). Thus, peak values $>1$ imply spike correlations above background.

\section{Results}

\section{Electrical coupling in the TRN}

Many neurons of the TRN are electrically coupled to one another (Landisman et al., 2002). Studies in other parts of the CNS have shown that electrical coupling depends strongly on the spatial arrangement of neurons (Amitai et al., 2002; Devor and Yarom, 2002), so we measured the distance-dependence of coupling in

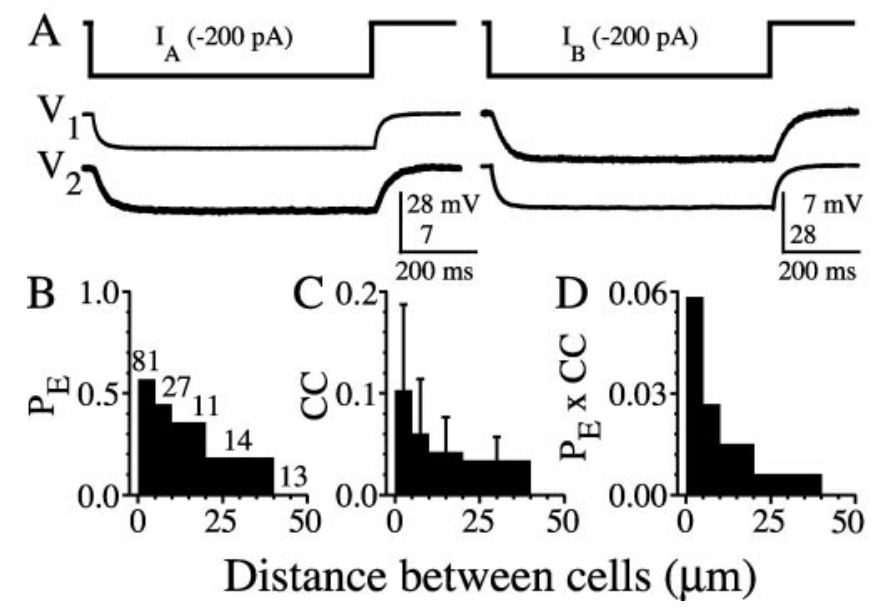

Figure 1. The spatial extent of electrical coupling in the TRN. $A$, Injection of hyperpolarizing current $(-200 \mathrm{pA})$ into one cell of an electrically coupled TRN pair results in a voltage deflection of the electrically coupled cell. Injections into cell $1\left(I_{A}\right.$, left) and cell 2 ( $I_{B}$, right) yielded essentially identical voltage deflections, indicating a symmetrical junction. $B-D$, The probability of coupling $\left(P_{E}\right.$; coupled pairs per measured pairs), coupling coefficient $(C C)$, and total coupling strength $\left(P_{\mathrm{E}} \times C \mathrm{C}\right)$ is strongly dependent on intersomatic distance.

the TRN. Electrical coupling between cell pairs was assessed by passing long ( $600 \mathrm{msec}$ ) hyperpolarizing current steps into one cell and measuring the corresponding voltage deflections in both cells (Fig. 1A). The sample of closely spaced pairs gathered for this study had a much higher incidence of coupling (71 of 100 pairs; $71 \%$ ) and was, on average, coupled more strongly (mean coupling coefficient $=0.11 \pm 0.08$ ) than the sample of TRN cells that we reported previously (28 of 90 pairs, or $31 \%$; mean coupling coefficient $=0.032 \pm 0.027$ ) (Landisman et al., 2002). The differences between our two studies are primarily attributable to the mean distances between the sampled neurons. Our previous sample included cell somata commonly separated by $10-30 \mu \mathrm{m}$ (measured edge to edge), whereas the current sample primarily consisted of very closely apposed cells ( $<5 \mu \mathrm{m}$ apart).

Indeed, there was a strong correlation between intersomatic distance and both the incidence and strength of coupling. We quantified this relationship by combining data from the present and previous studies. Both the probability of electrical coupling $\left(P_{\mathrm{E}}\right)$ (Fig. $\left.1 B\right)$ and the coupling coefficient $(C C)$ (Fig. 1C) decreased markedly with distance $(x)$, and electrical coupling was never observed at distances $>40 \mu \mathrm{m}$ ( $n=13$ pairs $)$. The product $P_{\mathrm{E}}(x) \times C C(x)$ is proportional to the total coupling conductance that a cell receives from all of its coupled neighbors at distance $x$ (Amitai et al., 2002). This product is almost an order of magnitude lower for cells spaced $20-40 \mu \mathrm{m}$ apart compared with those $<5 \mu \mathrm{m}$ apart (Fig. 1D).

Single action potentials in one neuron evoked obvious electrical postsynaptic potentials ("spikelets") in a second neuron if the coupling coefficient was greater than $\sim 0.10$ (Fig. $2 A$ ). To eliminate fast chemical synaptic communication, recordings were made in the presence of antagonists of ionotropic glutamate receptors (AP5, DNQX) and $\mathrm{GABA}_{\mathrm{A}}$ receptors (picrotoxin). Spikelets were observed in $76 \%$ of coupled pairs and ranged in amplitude from 0.10 to $1.82 \mathrm{mV}$, with a mean of $0.47 \pm 0.34 \mathrm{mV}(n=$ 53 pairs). TRN neurons generate intrinsic bursts of spikes, particularly on the rebound from a period of hyperpolarization (Bal and McCormick, 1993). When we stimulated neurons with hyperpolarizing current steps, the bursts evoked on repolarization had, on average, $4.1 \pm 1.4$ spikes per burst $(n=168$ cells $)$. The 

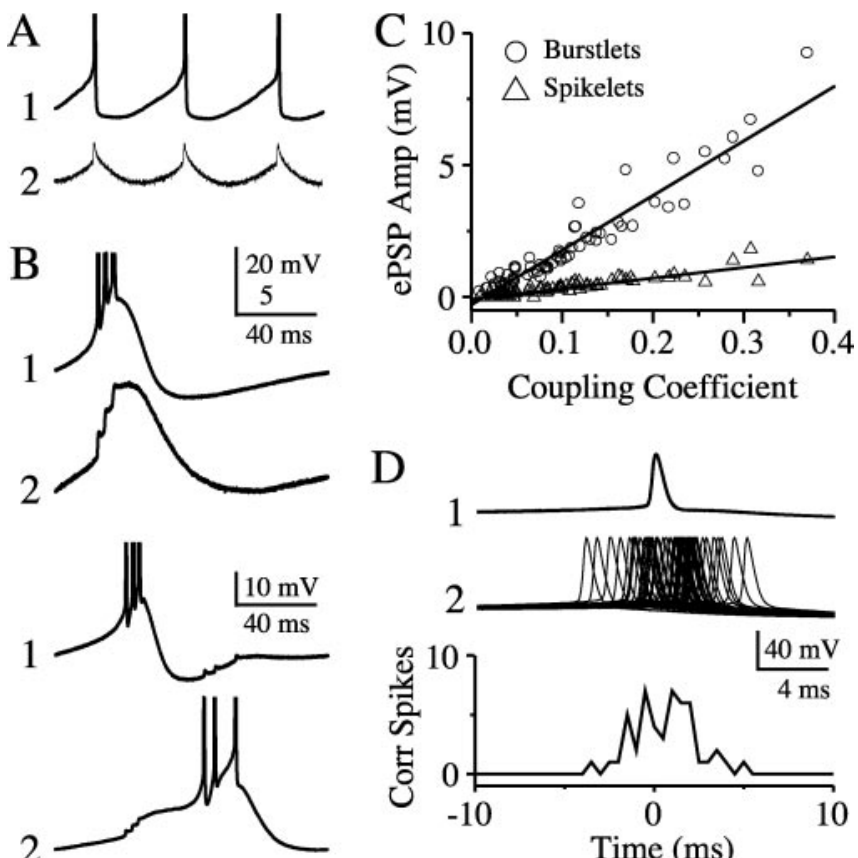

D

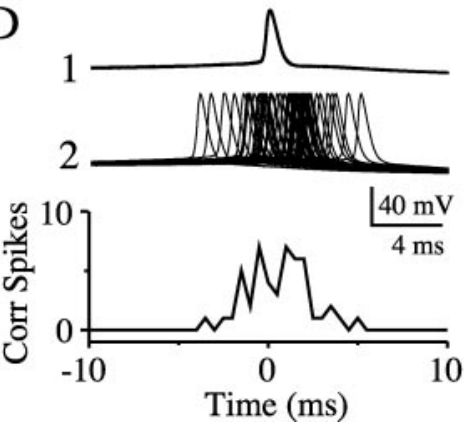

Figure 2. Electrical postsynaptic potentials. Electrically coupled pairs exhibited a range of electrical postsynaptic potentials (ePSPs) in the absence of fast chemical transmission. $A$, Single spikes in cell 1 produced sharp postsynaptic spikelets in cell 2. B, Spike bursts in cell 1 triggered robust burstlet responses in cell 2 (top two traces); burstlets were capable of eliciting postsynaptic spikes (bottom traces). C, Plot of the amplitudes of spikelets and burstlets versus coupling coefficient for 68 neuron pairs. The slope of the burstlet regression line is $\sim 5 \times$ that of the spikelet data. $D$, Single spikes of electrically coupled neurons can closely synchronize. Depolarizing current was injected into both cells to induce mean rates of $\sim 10 \mathrm{~Hz}$. Spikes from cell 1 were used to trigger overlays of spikes in cell 2 (top traces); these show clustering around 0 msec, which is reflected in the spike cross-correlogram (bin size $=0.5 \mathrm{msec}$; bottom graph). Action potential amplitudes in $A$ and $B$ are truncated.

electrical postsynaptic potentials evoked by such bursts ("burstlets") typically consisted of summated spikelets and a slower component corresponding to the low-threshold spike generated by the presynaptic cell (Fig. $2 B$, top traces). Burstlets readily triggered spiking in coupled neurons that were near threshold (Fig. $2 B$, bottom traces). In contrast to spikelets, burstlets were seen in all electrically coupled pairs tested $(n=68)$. Some pairs $(n=17)$ with relatively weak electrical coupling (mean coupling coefficient $=0.034 \pm 0.015$ ) showed reliable burstlets in the absence of obvious spikelets. The sizes of spikelets and burstlets generated by each neuron were linearly correlated with the coupling coefficient of that cell to the spike per burst-generating presynaptic cell (Fig. 2C) ( $r=0.91$ and 0.95 , respectively; $p<0.0001$ for both). The peak amplitudes of burstlets ranged from 0.23 to $9.25 \mathrm{mV}$ and were, on average, 5.1 times larger than the amplitudes of spikelets recorded in the same neurons. On average, the area under each burstlet was $25 \times$ larger than the area of its accompanying spikelet (mean burstlet area was $89.0 \pm 48.1 \mathrm{mV} \times$ msec; mean spikelet area was $3.5 \pm 2.1 \mathrm{mV} \times$ msec; $n=21$ ).

Despite the small size of spikelets, single spikes in one neuron could also strongly entrain the spiking in an electrically coupled neighbor. Depolarizing current was applied to each of a pair of TRN cells to generate similar mean firing rates $(\sim 10 \mathrm{~Hz})$. Crosscorrelating the spikes of the two cells showed a strong tendency for firing probability to peak at a phase lag close to zero (Fig. 2D), similar to the behavior of electrically coupled interneurons in neocortex (Galarreta and Hestrin, 1999; Gibson et al., 1999).
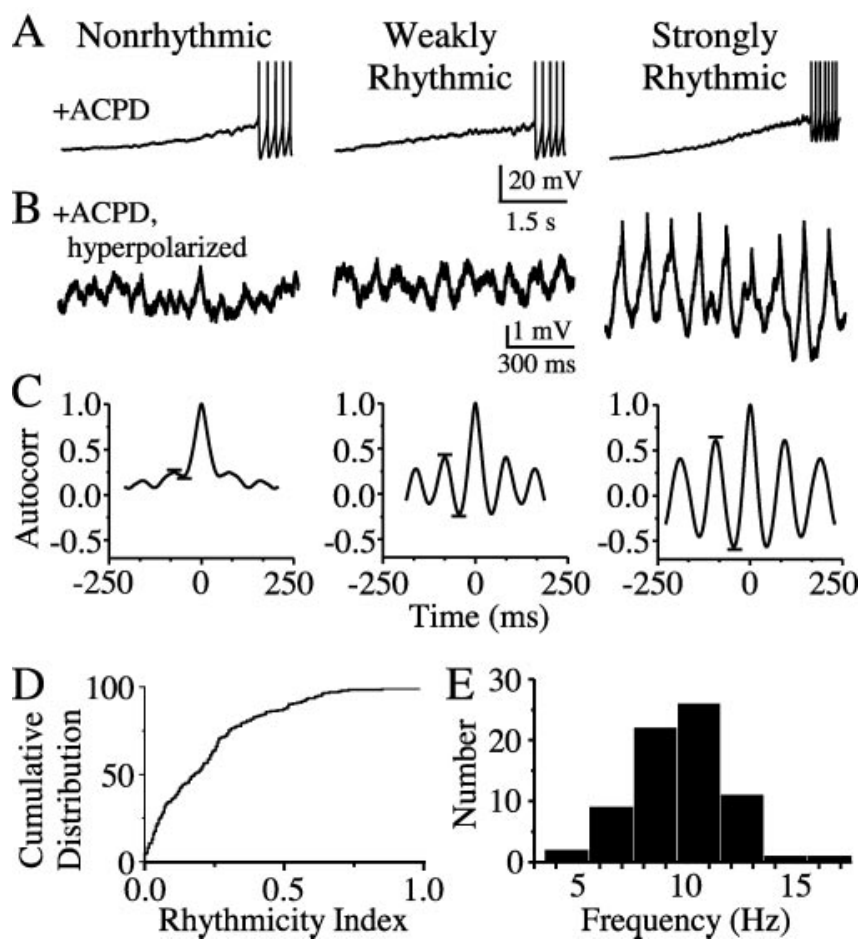

Figure 3. mGluR agonists differentially affect TRN neurons. $A$, The mGluR agonist ACPD (50 $\mu \mathrm{m}$ ) strongly depolarized and triggered spiking in all neurons tested. No relationship was seen between the magnitude of depolarizations and spiking frequency across cells. Spike amplitudes are truncated. $B$, Steady hyperpolarizing current in the presence of ACPD revealed a range of subthreshold rhythmicity; same cells as shown in A. C, Autocorrelograms based on 5 sec epochs of ACPD induced rhythmicity in the presence of steady hyperpolarizing current (same cells as shown in $A$ and $B$ ). Horizontal lines highlight the primary autocorrelogram side peaks from which subthreshold rhythmicity index was calculated. These examples illustrate nonrhythmic (rhythmicity index $=0.03$ ), weakly rhythmic $(0.30)$, and strongly rhythmic $(0.56)$ neurons. $D$, Cumulative histogram of rhythmicity scores from all cells tested $(n=202)$. $E$, Histogram showing distribution of peak frequency of subthreshold ACPD activity for all rhythmically responding cells (subthreshold rhythmicity index $\geq 0.25 ; n=74$ ).

\section{Subthreshold rhythms in TRN neurons}

Neurons of the TRN are sensitive to mGluR agonists (Lee and McCormick, 1997; Cox and Sherman, 1999). We found that bath application of the mGluR agonist ACPD $(50 \mu \mathrm{M})$ strongly depolarized all TRN neurons sampled and invariably triggered spiking (Fig. 3A). The mean ACPD-induced spiking frequency was $18.5 \pm 5.6 \mathrm{~Hz}( \pm \mathrm{SD} ; n=14)$. When neurons were hyperpolarized with steady current in the continued presence of ACPD, many of them generated rhythmic subthreshold fluctuations that lasted $\sim 3-5 \mathrm{~min}$, whereas others did not (Fig. 3B). Rhythms were often evident without applied hyperpolarizing current (Fig. 3A; see Fig. $7 A, C$ ) and just below spike threshold (see Fig. $5 C$ ). The subthreshold fluctuations were highly regular, which was reflected in the prominent side peaks of their autocorrelograms (Fig. 3C). We defined a "subthreshold rhythmicity index" as onehalf of the peak-to-peak amplitude adjacent to the central peak of the autocorrelogram; the index thus ranges from 0.00 (nonrhythmic) to 1.00 (perfectly rhythmic). The peak frequency of ACPDinduced oscillations among TRN cells with a subthreshold rhythmicity index $\geq 0.25$ ranged from 4.4 to $16.0 \mathrm{~Hz}$, with a mean of $9.5 \pm 2.2 \mathrm{~Hz}$ (Fig. 3E). The frequency of ACPD-induced spiking (assessed while cells were allowed to depolarize ad libitum in the presence of agonist) did not correlate with the rhythmicity index (assessed while cells were hyperpolarized with current to justsubthreshold levels). This suggests that the variability of sub- 

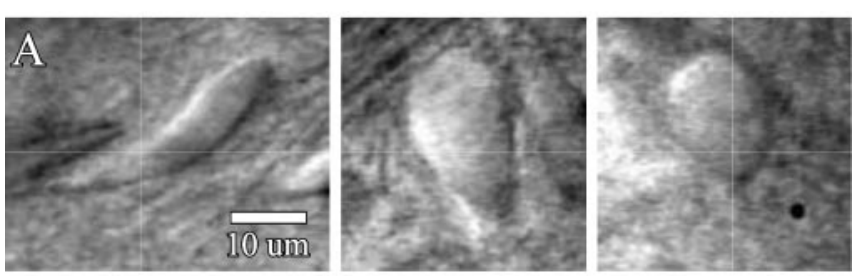

B Nonrhythmic Cell
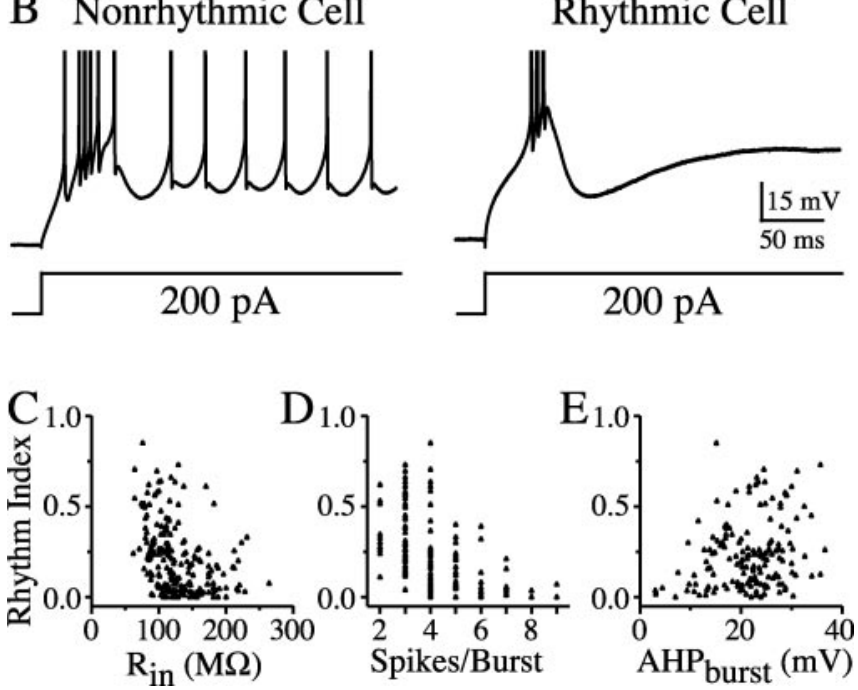

Figure 4. Physiological properties of rhythmically responsive cells. A, IR-DIC images of TRN neurons showing the range of soma shapes. Neither the shape nor size of somata was correlated with the strength of ACPD-induced rhythmicity. $B$, Example of bursts from a rhythmic and nonrhythmic TRN cells. Action potentials are truncated. $C$, Input resistance was negatively correlated with rhythmicity index ( $n=202$ cells). $D$, The number of action potentials per burst was negatively correlated with rhythmicity index ( $n=168$ cells). $E$, The amplitude of the burst after-hyperpolarization AHP $_{\text {burst }}$, measured as the difference in voltage from the crest of the burst to the following voltage trough) was positively correlated with rhythmicity index ( $n=$ 158 cells). $R_{\text {in }}$, Input resistance.

threshold rhythmicity was not caused by a differential sensitivity of TRN cells to ACPD.

The TRN neurons that we sampled were morphologically and physiologically heterogeneous, and we searched for cellular features predictive of mGluR-induced rhythmicity. Soma shape and size vary widely within the TRN, as histological studies have long documented (Ohara and Lieberman, 1985; Spreafico et al., 1991). Among our recorded neurons, the ratio of the somatic diameter along the narrow axis $(d)$ to diameter along the long axis $(D)$ ranged from 0.19 (long, thin, fusiform) to 1.00 (round) (Fig. 4A). Approximating soma size as the area $(A)$ of an ellipsoid, $A=$ $\pi(0.5 D)(0.5 d)$, neurons ranged from 141 to $503 \mu \mathrm{m}^{2}$. Neither somatic shape $(d / D)$ nor area predicted the degree of ACPDinduced rhythmicity among TRN cells. Passive membrane properties also varied across neurons. Resting membrane potential ranged from -50 to $-72 \mathrm{mV}$ but did not correlate with ACPD responsiveness. Input resistance, however, which varied from 62 to $264 \mathrm{M} \Omega$, was strongly and inversely correlated with ACPDinduced rhythmicity $(r=-0.37 ; p<0.0001)$.

Intrinsic physiological characteristics, in particular spikefrequency adaptation and the tendency to generate spike bursts, varied widely across TRN cells. To quantify these, we first held each neuron at relatively depolarized $(-50$ to $-55 \mathrm{mV})$ membrane potentials and tested them with suprathreshold depolarizing current pulses $(600 \mathrm{msec})$. Stepping the current amplitudes from 100 to $600 \mathrm{pA}$ generated final, adapted firing frequencies
$\left(F_{\mathrm{f}}\right)$ with means of $\sim 10-70 \mathrm{~Hz}$, respectively, with an approximately linear dependence of frequency on amplitude over this range. The extent of spike-frequency adaptation during these pulses was calculated as the ratio of $F_{\mathrm{f}}$ to the initial firing frequency $\left(F_{\mathrm{i}}\right)$. The intensity of the stimulus was adjusted to elicit an $F_{\mathrm{f}}$ value between 20 and $30 \mathrm{~Hz} . F_{\mathrm{f}} / F_{\mathrm{i}}$ tested in the absence of ACPD ranged from 0.37 to 1.13 , but this was not correlated with the rhythmicity index measured in the presence of ACPD.

TRN cells typically generate rebound bursts when released from hyperpolarized membrane potentials (McCormick and Prince, 1986; Huguenard and Prince, 1992). When initially held at -70 to $-75 \mathrm{mV}$ and then stimulated with a $200 \mathrm{pA}$ pulse in the absence of ACPD, all TRN cells produced at least one burst consisting of several fast action potentials riding on a slower lowthreshold spike (Fig. $4 B$ ). Bursts from different neurons varied in the number of spikes generated and in the magnitude of the post-burst afterhyperpolarization ( $\mathrm{AHP}_{\text {burst }}$ ) (Avanzini et al., 1989). The subthreshold rhythmicity index was negatively correlated with the magnitude of the burst (Fig. 4D) $(r=-0.47 ; p<$ $0.0001)$ and positively correlated with the $\mathrm{AHP}_{\text {burst }}$ (Fig. 4E) $(r=$ 0.26 ; $p<0.001)$. These results suggest that TRN neurons are physiologically diverse and that the ion currents responsible for generating brief bursts with large AHPs may be an integral feature of mGluR-mediated rhythmogenesis.

\section{Synchrony in the TRN}

Electrical coupling can mediate close synchronization of subthreshold oscillations in neocortical interneurons (Beierlein et al., 2000) and inferior olivary neurons (Benardo and Foster, 1986; Llinás and Yarom, 1986; Long et al., 2002; De Zeeuw et al., 2003). We tested for synchrony between pairs of closely neighboring and electrically coupled TRN neurons when both cells exhibited rhythmic responses to ACPD. When spiking was suppressed with steady hyperpolarizing current, rhythmic responses of coupled TRN pairs showed strongly synchronized fluctuations of membrane voltage (Fig. 5A). In the absence of hyperpolarizing current, the spiking activity of such cell pairs was also strongly correlated (Fig. 5B).

The patterns of ACPD-induced subthreshold rhythms and spikes were very similar, suggesting strongly that the subthreshold activity was driving the spikes. The best evidence for this came from paired recordings that demonstrated subthreshold and suprathreshold activity simultaneously. Shortly after ACPD was applied to the neurons shown in Figure $5 C$, both generated well correlated subthreshold rhythms. As the neurons continued to depolarize, cell 1 began to generate rhythmic spike doublets (i.e., two spikes per subthreshold cycle), each of which was closely correlated with the peaks of the subthreshold rhythms in cell 2 (similar behavior can be seen in the paired recordings of Figs. $7 \mathrm{~A}$ and $9 D$, left panel). Spike doublets were common; both cells of the pair shown in Figure $5 B$ also generated doublets. Across a sample of single-neuron recordings in ACPD, the coefficient of variation of the intervals between spikes was positively correlated with the subthreshold rhythmicity index measured in the same cells (Fig. 6A) $(r=0.74 ; p<0.005)$. This is also consistent with the hypothesis that subthreshold rhythms and neuronal spiking were interactive. Furthermore, because subthreshold rhythms tended to be correlated between pairs of coupled cells, the spikes generated by those cells were also well correlated. Figure $6 \mathrm{~B}$ plots data from eight paired recordings made in ACPD (or, in one case, after a brief tetanic stimulus; see below) (Fig. 7). In each case, samples of spiking behavior and subthreshold activity (while cells were hyperpolarized) were recorded sequentially. The graph 

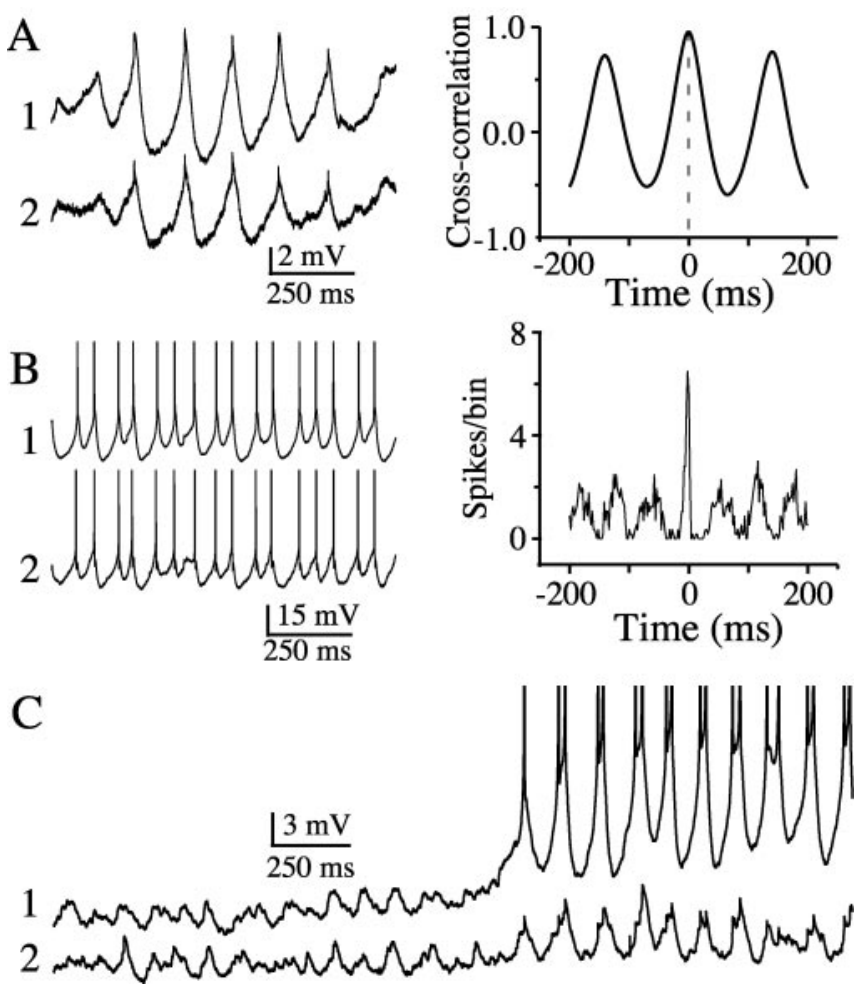

Figure 5. Subthreshold rhythms can synchronize spikes. A, A hyperpolarized pair of TRN cells that show strongly synchronous and rhythmic subthreshold activity in response to ACPD application, as reflected in the corresponding cross-correlogram (values for each bin were normalized by the mean number of spikes per bin). B, ACPD-induced spike synchrony in the absence of hyperpolarizing holding current. Action potentials are truncated in these traces. C, Paired recordings during ACPD-induced rhythms. Initially both cells generated well synchronized subthreshold rhythms; as cells depolarized slightly, cell 1 began to spike. Rhythmic spikes in cell 1 were consistently well correlated with the peaks of the subthreshold rhythms in cell 2.

shows that the correlation coefficients for subthreshold rhythms were positively correlated with the magnitude of spike synchrony $(r=0.84 ; p<0.02)$.

We tested whether endogenous glutamate could also trigger synchronous mGluR-dependent rhythms. A previous study showed that brief tetanic stimulation of corticothalamic axons could evoke slow, mGluR-dependent depolarization of thalamic relay neurons (McCormick and von Krosigk, 1992). We applied similar stimuli $(20-30$ shocks at $100 \mathrm{~Hz})$ to the internal capsule in the presence of AP5, DNQX, and picrotoxin to eliminate fast ionotropic synaptic components. For these experiments the bathing solution also contained $6 \mathrm{~mm}\left[\mathrm{~K}^{+}\right]$(elevated from the normal baseline of $3 \mathrm{~mm}$ ) to enhance excitability. Tetanic stimulation caused all TRN neurons to depolarize and spike repetitively for several seconds (Fig. 7A). In a subset of cells (11 of 36; $31 \%$ ) held slightly hyperpolarized to eliminate spiking after the stimulus, tetanic stimulation caused a rhythmic depolarization lasting from 2 to $>20 \mathrm{sec}$ (Fig. $7 B$ ). The mean frequency of the subthreshold tetanus-induced rhythms $(8.7 \pm 3.6 \mathrm{~Hz} ; n=11)$ is similar to those induced by ACPD $(7.4 \pm 2.2 \mathrm{~Hz} ; n=74)$. Furthermore, tetanic stimuli induced highly correlated subthreshold rhythms (Fig. 7C) as well as tightly correlated spiking (Fig. 7A) in pairs of neurons that were strongly coupled electrically. The tetanus-induced rhythms were blocked by MCPG (1 mM), an antagonist of groups I and II mGluRs $(n=4)$ (Fig. $7 B)$. In two cells held long enough to wash out the MCPG, tetanus-evoked rhythmicity was partially restored.

\section{Small synchronous clusters in TRN}

To address the extent to which electrical coupling may synchronize rhythms within the TRN, we plotted the coupling coefficient of TRN pairs against the cross-correlation of the ACPD-induced rhythmic activity (Fig. 8). These data show that electrical coupling strength and the degree of synchrony of ACPD-induced rhythmicity are strongly correlated $(r=0.71 ; p<0.0001)$.

The steep distance-dependence of electrical coupling (Fig. 1) and the correlation between coupling strength and the synchrony of subthreshold activity (Fig. 8) suggest that synchronous clusters of TRN neurons may be very small. To test this hypothesis, we studied pairs in which both neurons had a subthreshold rhythmicity index $\geq 0.25$ (Fig. 9). Among 13 such pairs in which intersomatic distances were $\leq 20 \mu \mathrm{m}, 12$ were electrically coupled (coupling coefficient $=0.14 \pm 0.09$ ), and the mean correlation coefficient for subthreshold rhythms was $0.56 \pm 0.22$ (Fig. 9A). Pairs with intersomatic distances ranging from 25 to $100 \mu \mathrm{m}$ (average $55 \pm 24 \mu \mathrm{m})$ were never electrically coupled $(n=8$ pairs), and all had correlation coefficients $<0.10$ (mean of $0.03 \pm$ 0.04 ; i.e., not significant) (Fig. $9 B$ ). Figure $9 C$ shows that subthreshold rhythms were only correlated when cell-cell spacing was $\leq 20 \mu \mathrm{m}$ and when the cells were electrically coupled. Spiketriggered averaging between closely apposed, electrically coupled cell pairs in the presence of ACPD revealed slowly ramping subthreshold depolarizations and fast spikelets (Fig. 9D). Noncoupled neurons, with larger intersomatic distances, showed no such relationship.

\section{Discussion}

We have identified several novel features of neuronal interaction within the TRN. Electrical synapses were strong and common between pairs of neurons, but only over very localized spatial domains. In addition, when mGluRs were activated, a subpopulation of TRN cells generated $5-15 \mathrm{~Hz}$ rhythms that were synchronized on a local scale via electrical synapses. These results suggest that electrically coupled neuronal clusters may be a major determinant of the spatial and temporal activity patterns of TRN.

The highly localized nature of electrical coupling in the TRN is a surprising observation. Similar measurements made in the neocortex showed that coupling within two different networks of inhibitory interneurons was much more widespread than that in the TRN, extending to intersomatic distances of $\sim 200 \mu \mathrm{m}$ (Amitai et al., 2002). The distance-dependence of electrical coupling in the inferior olivary nucleus, however, is about as tightly localized as that in the TRN (Devor and Yarom, 2002). It is not clear what determines the distance-dependence of coupling. Gap junctions have not yet been observed in the TRN, but their presence can be inferred from the Cx36-dependence of coupling (Landisman et al., 2002). The subcellular location of Cx36 in TRN is not known. By analogy with cortical inhibitory cells (Sloper and Powell, 1978; Tamas et al., 2000), gap junctions are most likely to be located at dendrodendritic or dendrosomatic sites. The dendrites of TRN cells are typically several hundred micrometers in length (Scheibel and Scheibel, 1966; Steriade et al., 1997), yet measurable coupling was limited to intersomatic distances of $40 \mu \mathrm{m}$, so it seems likely that electrical synapses preferentially form at very proximal locations rather than on more distal dendrites. It is also possible that distal electrical synapses are too weak and electrotonically remote to be detectable using present techniques. Even if this is the case, very distal gap junctions could influence the dendritic processing of chemical synaptic inputs, the propagation of dendritic spikes, or coordination of subthreshold activity among the local dendritic branches of coupled neurons. Another possibility 
is that slicing the tissue caused a significant number of coupled dendrites to be eliminated.

One interesting feature of electrical synapses within the TRN was the extent to which the electrical postsynaptic potential was affected by the intrinsic cellular properties. When a presynaptic TRN cell bursts, the postsynaptic response in a coupled cell is $\sim 5 \times$ greater in peak amplitude and $25 \times$ greater in area than the response to a single presynaptic spike. This difference is attributable to the low-pass filtering characteristics of TRN coupling (Landisman et al., 2002). The envelope of the low-threshold spike component of the burst is a much slower signal than the fast sodium action potentials, and so electrotonic coupling seems best adapted for propagating bursts through the TRN circuit. Thus, coupling may play a role in coordinating the activity of TRN cells at times when burst firing is most prevalent, such as during sleep or seizure states (Bal and McCormick, 1993; Steriade, 2001), and perhaps during certain waking conditions when bursting has been observed in thalamic relay cells (Fanselow et al., 2001; Sherman and Guillery, 2001; Swadlow and Gusev, 2001). In contrast, during aroused states when TRN cells are relatively depolarized and firing tonic action potentials, the influence of single spikes on coupled neighbors may be more spatially restricted. The interaction between intrinsic membrane properties and the low-pass filtering characteristics of electrical synapses may dynamically modulate the extent of coordination within the TRN during different levels of arousal.

Our experiments were performed on juvenile animals because it became much more difficult to visualize the neurons as the density of myelin increased during maturity. Nevertheless, there are several reasons to expect that the mature TRN retains substantial electrotonic coupling: in situ hybridization shows strong expression of Cx36 mRNA in the older TRN (Condorelli et al., 2000); $\beta$-galactosidase reporter in Cx36 knock-out mice (Deans et al., 2001; Landisman et al., 2002) is well expressed in mature animals (our unpublished observations); and Cx36-dependent coupling between neocortical interneurons, which has properties very similar to the coupling between TRN cells, continues into maturity (Galarreta and Hestrin, 2002).

The thalamus can serve as a generator of rhythmic activity across a range of frequencies, depending on various behavioral and experimental factors (Steriade, 1997). It is very likely that the TRN is an essential component of the pacemaking mechanism of some thalamic rhythms, most notably sleep spindles. Various studies performed in relatively intact thalamic circuits are consistent with the view that spindle rhythms arise from an interplay between TRN bursting, TRN-mediated inhibition of its associated thalamic relay neurons, and re-excitation of TRN cells by the relay neurons (von Krosigk et al., 1993; Bal et al., 1995; Avanzini et al., 2000; McCormick, 2002). Computational models have demonstrated in principle that a network of mutually inhibitory TRN neurons could produce coordinated spindle-frequency oscillations (Wang and Rinzel, 1993; Destexhe et al., 1994); however, experiments on mice with impaired intra-TRN GABA receptors suggested that inhibition within the TRN may also desynchronize rhythms (Huntsman et al., 1999). A function for gap junctions in TRN is suggested by theoretical work suggesting that the addition of electrotonic coupling to a network of mutu-
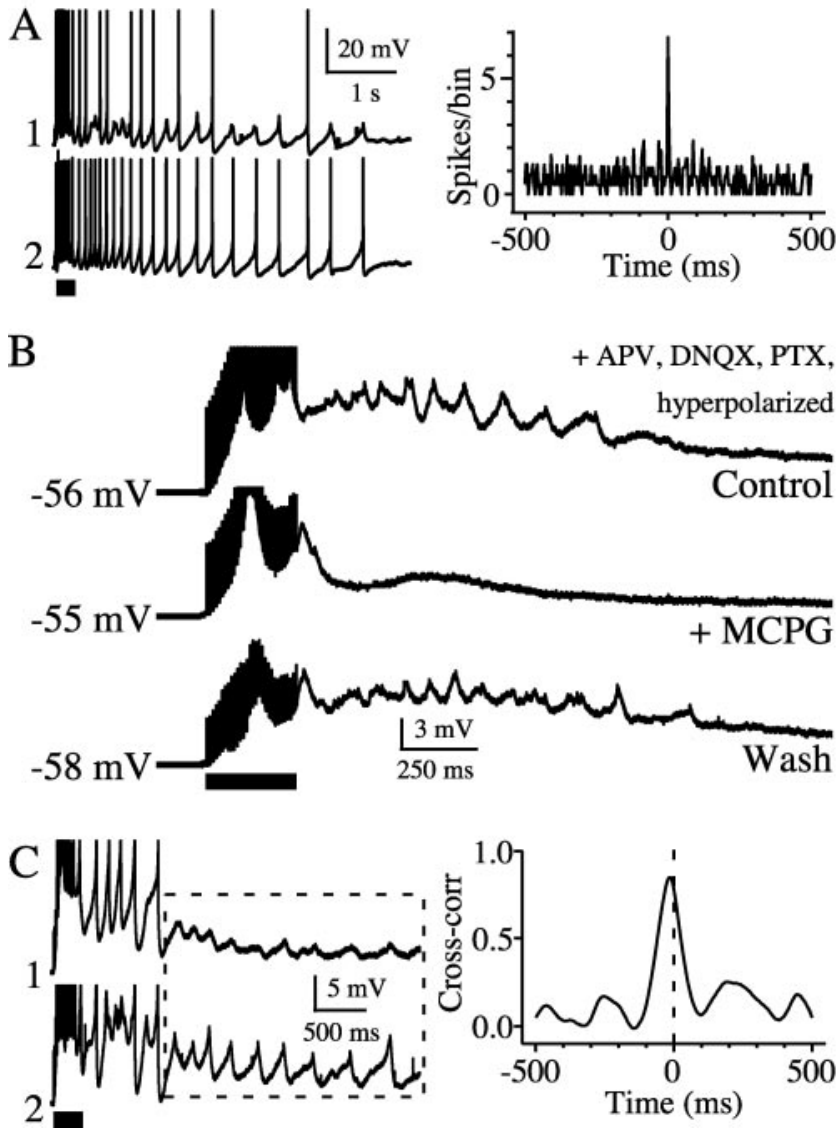

Figure 7. Tetanic stimulation evokes mGluR-induced rhythmicity. A, In the presence of AP5 (NMDA antagonist), DNQX (AMPA antagonist), and increased extracellular potassium (6 mm $\mathrm{KCl}$ ), tetanic stimulation of the internal capsule (bar) induced synchronous spiking in an electrically coupled TRN pair. Cross-correlogram is based on spikes generated after the tetanic stimulus (values for each bin were normalized by the mean number of spikes per bin). $B$, In the presence of steady hyperpolarizing current, tetanic stimuli elicited prolonged rhythmic depolarization that was reversibly blocked by the mGluR antagonist MCPG. C, Stimulation-induced subthreshold rhythmicity was correlated in an electrically coupled neuron pair.

ally inhibitory neurons can stabilize synchronous firing states (Lewis and Rinzel, 2003).

Our results complement previous work. We have demonstrated that mGluR activation induces a subpopulation of TRN neurons to generate rhythmic oscillations of $5-15 \mathrm{~Hz}$ in the ab- 


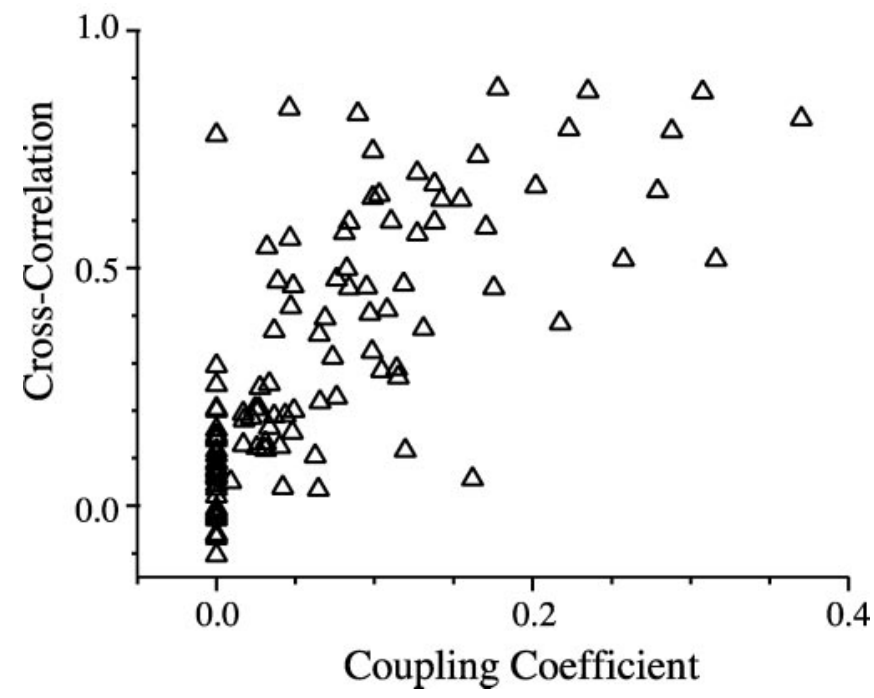

Figure 8. Electrical coupling strength correlates with synchrony of subthreshold rhythms ( $n=100$ neuron pairs).

sence of chemical synaptic communication. These frequencies closely match the 7-14 Hz rhythms of spindles generated in intact thalamic circuits (Bal and McCormick, 1993; Steriade et al., 1997). It is likely that activation of mGluRs alters certain membrane conductances and thus induces an intrinsic rhythmic state in subsets of TRN neurons. A strong predictor of mGluRinduced rhythmicity was the amplitude of the $\mathrm{AHP}_{\text {burst }}$ under normal conditions. Potassium currents underlying the $\mathrm{AHP}_{\text {burst }}$, along with the low-threshold calcium current that drives the burst, may contribute to the mechanisms of mGluR-induced rhythmicity. ACPD-induced rhythmicity has been reported for other systems, in particular the hippocampus (Whittington et al., 1995) and neocortex (Beierlein et al., 2000; Deans et al., 2001). Furthermore, evoked rhythms of $\sim 8-15 \mathrm{~Hz}$ follow mGluR activation of cat thalamic relay neurons in vitro (Hughes et al., 2002), caused in part by a decrease in leak conductance leading to membrane depolarization and enhanced excitability (McCormick and von Krosigk, 1992; Turner and Salt, 2000). Regardless of its ionic mechanisms, our results suggest that modulator-induced alterations of TRN membranes may contribute significantly to the generation of spindle-frequency oscillations in the thalamus.

The mGluR-induced TRN rhythms were tightly synchronized over a very circumscribed area. Correlations between pairs of rhythmic neurons fell to chance levels at distances as short as 25 $\mu \mathrm{m}$ (Fig. 9). This is much smaller than the spatial scale of mGluRinduced rhythms among low-threshold spiking interneurons in the neocortex, where the synchrony of membrane fluctuations can span $>300 \mu \mathrm{m}$ (Beierlein et al., 2000). It is also much more localized than the TRN synchrony observed during spindle-like activity in more intact thalamic circuits in vitro (McCormick and Bal, 1997) and far smaller than thalamic spindle synchrony in the intact brain (Contreras et al., 1996). The different spatial scales of mGluR-dependent synchrony in TRN and neocortex are well matched, however, to the dimensions of electrical coupling in these two regions. Our data strongly suggest that the TRN is composed of relatively small clusters of electrically coupled cells that can synchronize rhythmic activity over relatively short distances; by comparison, the more widespread coupling among neocortical interneurons (Amitai et al., 2002) mediates a much more expansive synchrony of rhythms (Beierlein et al., 2000). Electrical synapses may serve to synchronize small clusters of

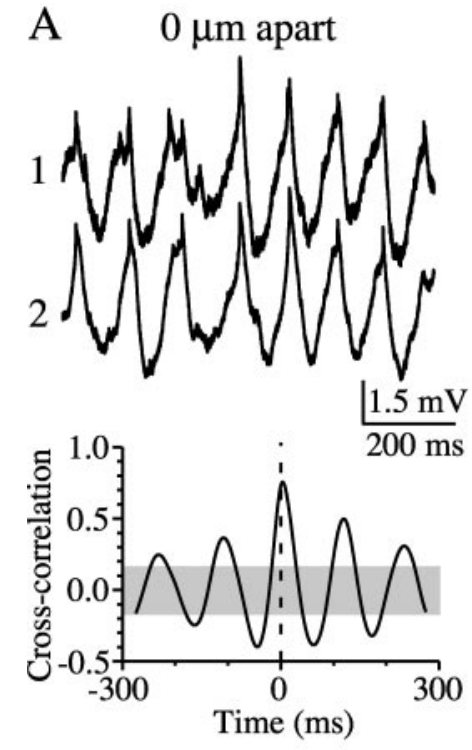

B $25 \mu \mathrm{m}$ apart
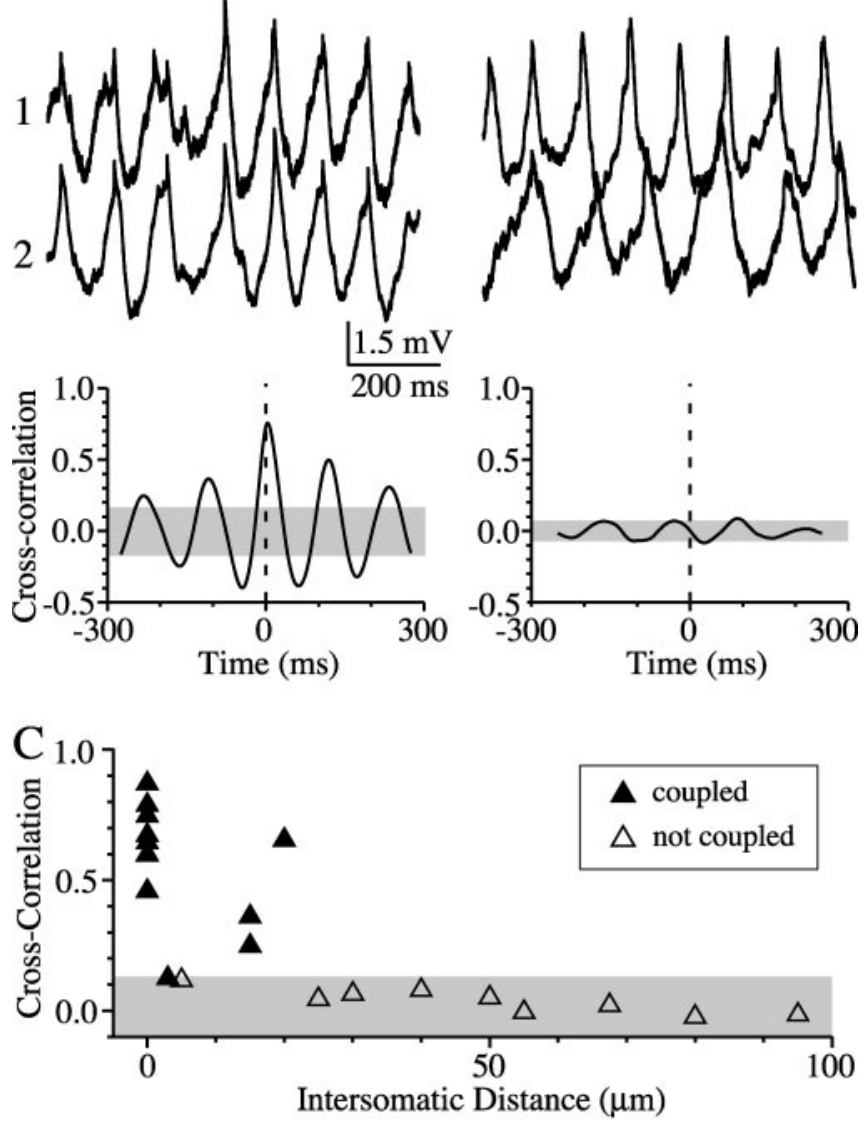

$\mathrm{D}$

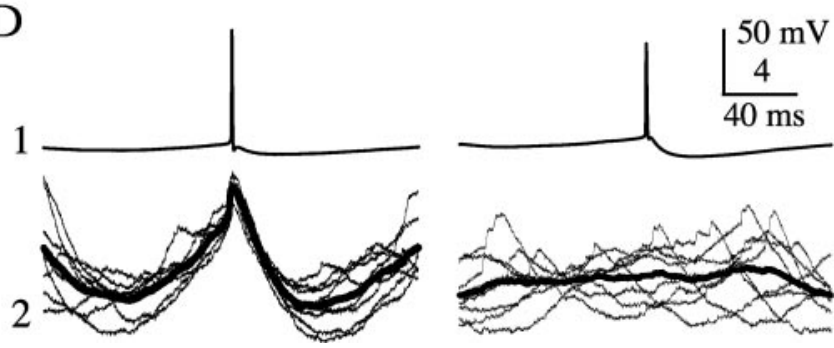

Figure 9. Localized clusters of synchronous activity within the TRN. Strongly synchronous ACPD-induced rhythms were common in neuron pairs that were closely spaced $(A)$ but not in pairs more widely spaced $(B)$. Mean frequencies of fluctuations in the cell pair $25 \mu \mathrm{m}$ apart were 7.8 and $10.6 \mathrm{~Hz}$, compared with $8.7 \mathrm{~Hz}$ in $A$. Cross-correlograms were calculated from 10 sec ACPD-induced rhythmic episodes that included the periods shown in top traces. C, Average cross-correlations of coupled (filled triangles; $n=12$ ) and noncoupled (open triangles; $n=9$ ) cell pairs in the presence of ACPD. Both electrical coupling and synchrony were a steep function of intersomatic distance. Shaded regions in all graphs represent the $95 \%$ confidence intervals calculated from randomly shuffled traces. D, Overlay of spike-triggered rhythmic events (bold line $=$ mean spike-triggered response). Spike-triggered pair from $25 \mu \mathrm{m}$ is the same shown in $A$ and $B$; spike-triggered data from $0 \mu \mathrm{m}$ were taken from a different pair $(C C=0.18)$.

TRN neurons during specific behavioral states, acting in concert with more long-range inhibitory connections within TRN that help to desynchronize the activity of neighboring coupled clusters (Sohal et al., 2000).

Synchronously rhythmic cell clusters within the TRN may be an effective means of influencing the activity of thalamocortical neurons on a fine-grained scale. Anatomical evidence suggests that the axons of TRN neurons with overlapping dendritic fields share thalamocortical targets (Pinault and Deschenes, 1998). The 
organized timing of the input onto thalamocortical neurons should allow for the generation of a powerful convergent inhibition onto thalamic relay nuclei. Rebound bursts in thalamocortical cells can feed back onto the TRN, serving to maintain network rhythms (McCormick and Bal, 1997).

\section{References}

Agmon A, Connors BW (1991) Thalamocortical responses of mouse somatosensory (barrel) cortex in vitro. Neuroscience 41:365-379.

Amitai Y, Gibson JR, Beierlein M, Patrick SL, Ho AM, Connors BW, Golomb D (2002) The spatial dimensions of electrically coupled networks of interneurons in the neocortex. J Neurosci 22:4142-4152.

Avanzini G, de Curtis M, Panzica F, Spreafico R (1989) Intrinsic properties of nucleus reticularis thalami neurones of the rat studied in vitro. J Physiol (Lond) 416:111-122.

Avanzini G, Panzica F, de Curtis M (2000) The role of the thalamus in vigilance and epileptogenic mechanisms. Clin Neurophysiol 111 [Suppl 2]:S19-26.

Bal T, McCormick DA (1993) Mechanisms of oscillatory activity in guineapig nucleus reticularis thalami in vitro: a mammalian pacemaker. J Physiol (Lond) 468:669-691.

Bal T, von Krosigk M, McCormick DA (1995) Role of the ferret perigeniculate nucleus in the generation of synchronized oscillations in vitro. J Physiol (Lond) 483:665-685.

Bal T, Debay D, Destexhe A (2000) Cortical feedback controls the frequency and synchrony of oscillations in the visual thalamus. J Neurosci 20:7478-7488.

Beierlein M, Gibson JR, Connors BW (2000) A network of electrically coupled interneurons drives synchronized inhibition in neocortex. Nat Neurosci 3:904-910.

Benardo LS, Foster RE (1986) Oscillatory behavior in inferior olive neurons: mechanism, modulation, cell aggregates. Brain Res Bull 17:773-784.

Blumenfeld H, McCormick DA (2000) Corticothalamic inputs control the pattern of activity generated in thalamocortical networks. J Neurosci 20:5153-5162.

Condorelli DF, Belluardo N, Trovato-Salinaro A, Mudo G (2000) Expression of Cx36 in mammalian neurons. Brain Res Brain Res Rev 32:72-85.

Contreras D, Destexhe A, Sejnowski TJ, Steriade M (1996) Control of spatiotemporal coherence of a thalamic oscillation by corticothalamic feedback. Science 274:771-774.

Cox CL, Sherman SM (1999) Glutamate inhibits thalamic reticular neurons. J Neurosci 19:6694-6699.

Crabtree JW (1999) Intrathalamic sensory connections mediated by the thalamic reticular nucleus. Cell Mol Life Sci 56:683-700.

Deans MR, Gibson JR, Sellitto C, Connors BW, Paul DL (2001) Synchronous activity of inhibitory networks in neocortex requires electrical synapses containing connexin36. Neuron 31:477-485.

De Biasi S, Frassoni C, Spreafico R (1988) The intrinsic organization of the ventroposterolateral nucleus and related reticular thalamic nucleus of the rat: a double-labeling ultrastructural investigation with gammaaminobutyric acid immunogold staining and lectin-conjugated horseradish peroxidase. Somatosens Res 5:187-203.

Deschenes M, Madariaga-Domich A, Steriade M (1985) Dendrodendritic synapses in the cat reticularis thalami nucleus: a structural basis for thalamic spindle synchronization. Brain Res 334:165-168.

Destexhe A, Contreras D, Sejnowski TJ, Steriade M (1994) A model of spindle rhythmicity in the isolated thalamic reticular nucleus. J Neurophysiol 72:803-818.

Destexhe A, Contreras D, Steriade M (1998) Mechanisms underlying the synchronizing action of corticothalamic feedback through inhibition of thalamic relay cells. J Neurophysiol 79:999-1016.

Devor A, Yarom Y (2002) Electrotonic coupling in the inferior olivary nucleus revealed by simultaneous double patch recordings. J Neurophysiol 87:3048-3058.

De Zeeuw CI, Chorev E, Devor A, Manor Y, Van Der Giessen RS, De Jeu MT, Hoogenraad CC, Bijman J, Ruigrok TJ, French P, Jaarsma D, Kistler WM, Meier C, Petrasch-Parwez E, Dermietzel R, Sohl G, Gueldenagel M, Willecke K, Yarom Y (2003) Deformation of network connectivity in the inferior olive of connexin 36-deficient mice is compensated by morphological and electrophysiological changes at the single neuron level. J Neurosci 23:4700-4711.

Fanselow EE, Sameshima K, Baccala LA, Nicolelis MA (2001) Thalamic bursting in rats during different awake behavioral states. Proc Natl Acad Sci USA 98:15330-15335.

Galarreta M, Hestrin S (1999) A network of fast-spiking cells in the neocortex connected by electrical synapses. Nature 402:72-75.

Galarreta M, Hestrin S (2002) Electrical and chemical synapses among parvalbumin fast-spiking GABAergic interneurons in adult mouse neocortex. Proc Natl Acad Sci USA 99:12438-12443.

Gibson JR, Beierlein M, Connors BW (1999) Two networks of electrically coupled inhibitory neurons in neocortex. Nature 402:75-79.

Hughes SW, Cope DW, Blethyn KL, Crunelli V (2002) Cellular mechanisms of the slow $(<1 \mathrm{~Hz})$ oscillation in thalamocortical neurons in vitro. Neuron 33:947-958.

Huguenard JR, Prince DA (1992) A novel T-type current underlies prolonged $\mathrm{Ca}(2+)$-dependent burst firing in GABAergic neurons of rat thalamic reticular nucleus. J Neurosci 12:3804-3817.

Huntsman MM, Porcello DM, Homanics GE, DeLorey TM, Huguenard JR (1999) Reciprocal inhibitory connections and network synchrony in the mammalian thalamus. Science 283:541-543.

Jacobsen RB, Ulrich D, Huguenard JR (2001) GABA(B) and NMDA receptors contribute to spindle-like oscillations in rat thalamus in vitro. J Neurophysiol 86:1365-1375.

Landisman CE, Long MA, Beierlein M, Deans MR, Paul DL, Connors BW (2002) Electrical synapses in the thalamic reticular nucleus. J Neurosci 22:1002-1009.

Lee KH, McCormick DA (1997) Modulation of spindle oscillations by acetylcholine, cholecystokinin and $1 S, 3 R$-ACPD in the ferret lateral geniculate and perigeniculate nuclei in vitro. Neuroscience 77:335-350.

Lewis TJ, Rinzel J (2003) Dynamics of spiking neurons connected by both inhibitory and electrical coupling. J Comput Neurosci 14:283-309.

Liu XB, Jones EG (1999) Predominance of corticothalamic synaptic inputs to thalamic reticular nucleus neurons in the rat. J Comp Neurol 414:67-79.

Llinás R, Yarom Y (1986) Oscillatory properties of guinea-pig inferior olivary neurones and their pharmacological modulation: an in vitro study. J Physiol (Lond) 376:163-182.

Long MA, Deans MR, Paul DL, Connors BW (2002) Rhythmicity without synchrony in the electrically uncoupled inferior olive. J Neurosci 22:10898-10905.

McCormick DA (2002) Cortical and subcortical generators of normal and abnormal rhythmicity. Int Rev Neurobiol 49:99-114.

McCormick DA, Bal T (1997) Sleep and arousal: thalamocortical mechanisms. Annu Rev Neurosci 20:185-215.

McCormick DA, Contreras D (2001) On the cellular and network bases of epileptic seizures. Annu Rev Physiol 63:815-846.

McCormick DA, Prince DA (1986) Acetylcholine induces burst firing in thalamic reticular neurones by activating a potassium conductance. $\mathrm{Na}-$ ture 319:402-405.

McCormick DA, von Krosigk M (1992) Corticothalamic activation modulates thalamic firing through glutamate "metabotropic" receptors. Proc Natl Acad Sci USA 89:2774-2778.

Ohara PT, Lieberman AR (1985) The thalamic reticular nucleus of the adult rat: experimental anatomical studies. J Neurocytol 14:365-411.

Pinault D, Deschenes M (1998) Projection and innervation patterns of individual thalamic reticular axons in the thalamus of the adult rat: a threedimensional, graphic, and morphometric analysis. J Comp Neurol 391:180-203.

Pinault D, Bourassa J, Deschenes M (1995) The axonal arborization of single thalamic reticular neurons in the somatosensory thalamus of the rat. Eur J Neurosci 7:31-40.

Sanchez-Vives MV, Bal T, McCormick DA (1997) Inhibitory interactions between perigeniculate GABAergic neurons. J Neurosci 17:8894-8908.

Scheibel ME, Scheibel AB (1966) The organization of the ventral anterior nucleus of the thalamus. A Golgi study. Brain Res 1:250-268.

Sherman SM, Guillery RW (2001) Exploring the thalamus. San Diego: Academic.

Shu Y, McCormick DA (2002) Inhibitory interactions between ferret thalamic reticular neurons. J Neurophysiol 87:2571-2576.

Slaght SJ, Leresche N, Deniau JM, Crunelli V, Charpier S (2002) Activity of thalamic reticular neurons during spontaneous genetically determined spike and wave discharges. J Neurosci 22:2323-2334.

Sloper JJ, Powell TP (1978) Gap junctions between dendrites and somata of 
neurons in the primate sensorimotor cortex. Proc R Soc Lond B Biol Sci 203:39-47.

Sohal VS, Huntsman MM, Huguenard JR (2000) Reciprocal inhibitory connections regulate the spatiotemporal properties of intrathalamic oscillations. J Neurosci 20:1735-1745.

Spreafico R, Battaglia G, Frassoni C (1991) The reticular thalamic nucleus (RTN) of the rat: cytoarchitectural, Golgi, immunocytochemical, and horseradish peroxidase study. J Comp Neurol 304:478-490.

Steriade M (2001) The sliced and intact brain. Cambridge, MA: MIT.

Steriade M, Domich L, Oakson G, Deschenes M (1987) The deafferented reticular thalamic nucleus generates spindle rhythmicity. J Neurophysiol 57:260-273.

Steriade M, McCormick DA, Sejnowski TJ (1993) Thalamocortical oscillations in the sleeping and aroused brain. Science 262:679-685.

Steriade M, Jones EG, McCormick DA (1997) Thalamus. Amsterdam: Elsevier.

Swadlow HA, Gusev AG (2001) The impact of "bursting" thalamic impulses at a neocortical synapse. Nat Neurosci 4:402-408.

Tamas G, Buhl EH, Lorincz A, Somogyi P (2000) Proximally targeted GABAergic synapses and gap junctions synchronize cortical interneurons. Nat Neurosci 3:366-371.
Turner JP, Salt TE (2000) Synaptic activation of the group I metabotropic glutamate receptor mGlul on the thalamocortical neurons of the rat dorsal lateral geniculate nucleus in vitro. Neuroscience 100:493-505.

Ulrich D, Huguenard JR (1996) Gamma-aminobutyric acid type B receptor-dependent burst-firing in thalamic neurons: a dynamic clamp study. Proc Natl Acad Sci USA 93:13245-13249.

von Krosigk M, Bal T, McCormick DA (1993) Cellular mechanisms of a synchronized oscillation in the thalamus. Science 261:361-364.

Wang XJ, Rinzel J (1993) Spindle rhythmicity in the reticularis thalami nucleus: synchronization among mutually inhibitory neurons. Neuroscience 53:899-904.

Whittington MA, Traub RD, Jefferys JG (1995) Synchronized oscillations in interneuron networks driven by metabotropic glutamate receptor activation. Nature 373:612-615.

Williams D (1953) A study of thalamic and cortical rhythms in petit mal. Brain 76:50-69.

Yen CT, Conley M, Hendry SH, Jones EG (1985) The morphology of physiologically identified GABAergic neurons in the somatic sensory part of the thalamic reticular nucleus in the cat. J Neurosci 5:2254-2268. 